\title{
The importance of internet usage for urologic patients
}

\author{
Cahit Sahin ${ }^{1}$, Murat Tuncer ${ }^{1}$, Ozgur Yazici ${ }^{1}$, Alper Kafkasli ${ }^{1}$, Utku Can ${ }^{1}$, Bilal Eryildirim ${ }^{1}$, \\ Orhan Koca $^{2}$, Kemal Sarica ${ }^{1}$ \\ ${ }^{1}$ Dr. Lutfi Kirdar Training and Research Hospital, Urology Clinic, Istanbul, Turkey; \\ ${ }^{2}$ Hydarpasa Numune Training and Research Hospital, Urology Clinic, Istanbul, Turkey.
}

\begin{abstract}
Summary Objectives: To evaluate Internet usage frequency, rate of searched diseases and impact of Internet derived data on future patientphysician relationship in patients applying to an Urology Department.

Methods: A well prepared questionnaire has been given to 1000 referring cases, out of which 589 accepted to participate on a volunteer basis to a face to face interview. Patients were divided into subgroups with respect to age, gender and as well as their educational and economical status. Regarding Internet, questions inquired the use of Internet, the point of view about it, opinions about healthcare system and most commonly urological diseases searched in Internet.

Results: Of 589 patients participating, 38.2\% reported access to the Internet; in relation to subgroup analysis of data, there was a statistically significant relationship between the use of Internet and age $(p<0.001)$, gender $(p=0.048)$, educational status $(p<0.001)$ and economical status of $(p=0.002)$ the cases evaluated. Diseasespecific information was most frequently sought: $18.2 \%$ searched for urolithiasis, $14.2 \%$ for non-cancer related kidney diseases, and $14.2 \%$ for urologic cancers.

Conclusions: Younger patients with higher educational status tended to use Internet and the majority of these cases share all these information with their physicians during their visit. These findings indicate that all physicians should consider this fact seriously and make their future plans in the light of internet based activities which provides numerous advantages.
\end{abstract}

KEY WORDS: Internet; Urologic patient; Urological diseases.

Submitted 2 February 2014; Accepted 31 March 2014

\section{INTRODUCTION}

Internet is a perfect tool which enables easy access to existing information in all parts of lives and to share it with whole world in a very practical manner (1). In addition to its extremely common usage in all parts of life, medical aspect of its usage also show an increasing popularity (2). In a recent study, it was shown that $74 \%$ of adult people in USA use Internet and out of them $90 \%$ were found to use it for medical purposes (3). A questionnaire study of Andreassen et al. about 7934 people in 7 different European countries reported that frequency of Internet usage and rate of searching for medical knowledge were $61 \%(81-42)$ and $71 \%(79-54)$, respectively (4).

Internet usage allows the patients to have the chance of following the disease course effectively by providing rapid, suitable, easy, real information about their diseases (5). Related with this subject, particularly, the patients with uro-oncological diseases search Internet in a more effective manner to obtain information concerning the etiology, treatment and follow up of the disease after first diagnosis of the pathology (6). They also tend to read some guideline information from Internet before referring to a physician. Parallel to these developments, traditional patient-physician relationship, which gives a passive position to the patient, has evolved in a situation where the patient came into a central position (7).

The aim of this study was to evaluate the Internet usage frequency and the rate of searched diseases along with the impact of Internet derived data on future patientphysician relationship in patients applying to an urology policlinic of a training and research hospital in a developing country.

\section{MATERIAL AND METHOdS}

Our present prospective study aimed to evaluate the use of Internet in detail among the patients referring with urological complaints to our outpatient department between June 2013 and July 2013. A well prepared questionnaire was given to 1000 referring cases, out of which 589 accepted to participate on a volunteer basis to a face to face interview.

The questionnaire had two parts consisting of questions concerning the demographic characteristics of the cases and other questions assessing the use of Internet in a detailed basis (Tables 1, 2). Patients were divided into subgroups with respect to age, gender and as well as their educational and economical status. Regarding Internet questions aimed to inquiry the use of Internet, point of view and opinions of patients about the healthcare system and most commonly searched urological diseases from the Internet (Table 2).

No conflict of interest declared. 
Table 1.

Demographic characteristics of the patients

\begin{tabular}{|c|c|c|c|c|c|c|c|c|}
\hline & & \multicolumn{2}{|c|}{$\begin{array}{c}\text { Total sample } \\
\text { (N = 589) }\end{array}$} & \multicolumn{2}{|c|}{$\begin{array}{l}\text { nternet users } \\
(+)(n=225)\end{array}$} & \multicolumn{2}{|c|}{$\begin{array}{l}\text { Internet users } \\
(-)(n=364)\end{array}$} & \\
\hline & & $n$ & $\%$ & $n$ & $\%$ & $n$ & $\%$ & \\
\hline Age (year) & $\begin{array}{c}<30 \\
30-60 \\
>60\end{array}$ & $\begin{array}{l}114 \\
298 \\
177\end{array}$ & $\begin{array}{l}19.4 \\
50.6 \\
30.0\end{array}$ & $\begin{array}{c}87 \\
122 \\
16\end{array}$ & $\begin{array}{c}76.3 \\
40.9 \\
9.0\end{array}$ & $\begin{array}{c}27 \\
176 \\
161\end{array}$ & $\begin{array}{l}23.7 \\
59.1 \\
91.0\end{array}$ & $\mathrm{a} 0.001 * *$ \\
\hline Gender & $\begin{array}{l}\text { Male } \\
\text { Female }\end{array}$ & $\begin{array}{l}390 \\
199\end{array}$ & $\begin{array}{l}66.2 \\
33.8\end{array}$ & $\begin{array}{c}160 \\
65\end{array}$ & $\begin{array}{l}41.0 \\
32.7\end{array}$ & $\begin{array}{l}230 \\
134\end{array}$ & $\begin{array}{l}59.0 \\
67.3\end{array}$ & a0.048* \\
\hline Educational status & $\begin{array}{l}\text { Primary school } \\
\text { Intermediate school } \\
\text { High school }\end{array}$ & $\begin{array}{c}441 \\
53 \\
95\end{array}$ & $\begin{array}{c}74.9 \\
9.0 \\
16.1\end{array}$ & $\begin{array}{c}115 \\
33 \\
77\end{array}$ & $\begin{array}{l}26.1 \\
62.3 \\
81.1\end{array}$ & $\begin{array}{c}326 \\
20 \\
18\end{array}$ & $\begin{array}{l}73.6 \\
37.7 \\
18.9\end{array}$ & $\mathrm{a} 0.001 * *$ \\
\hline Economical status & $\begin{array}{c}<1000 \mathrm{TL} \\
1000-4000 \mathrm{TL} \\
>4000 \mathrm{TL}\end{array}$ & $\begin{array}{c}210 \\
373 \\
6\end{array}$ & $\begin{array}{c}35.7 \\
63.3 \\
1.0\end{array}$ & $\begin{array}{c}71 \\
148 \\
6\end{array}$ & $\begin{array}{c}33.8 \\
39.7 \\
100.0\end{array}$ & $\begin{array}{c}139 \\
225 \\
0\end{array}$ & $\begin{array}{c}66.2 \\
60.3 \\
0.0\end{array}$ & b0.002** \\
\hline
\end{tabular}

Table 2.

Multiaspect evaluation of the information derived from the interner by the patients

\begin{tabular}{|c|c|c|c|}
\hline & & $\mathbf{n}$ & $\%$ \\
\hline \multirow[t]{7}{*}{ Do you use internet? } & No & 364 & 61.8 \\
\hline & Yes & 225 & 38.2 \\
\hline & Do you have e- mail address? & 169 & 75.1 \\
\hline & Do you check the internet related with your problem prior to the examination? & 165 & 73.3 \\
\hline & Do you share the healtcare information obtained from the internet with your physician? & 89 & 39.7 \\
\hline & Do you find the healthcare information derived from the internet as useful? & 173 & 77.2 \\
\hline & Do you rely on the healthcare information derived from the internet? & 119 & 53.1 \\
\hline
\end{tabular}

Patients being able to use Internet (almost every day or at least once in a week) have been accepted as true users. Patients between 18 and 90 years participating into the questionnaire study in a voluntarily basis have been included into the study program; patients with mental retardation, severe psychiatric disorders and illiterate ones were excluded from the study program. The study program has been approved by the Ethics Committee of the institution and a informed consent has been obtained from all cases included into the program.

Statistical analysis was performed with NCSS (Number Cruncher Statistical System) 2007\&PASS (Power Analysis and Sample Size) 2008 Statistical Software (Utah, USA). In addition to descriptive statistics (frequency, ratio), Chi-square and Fisher-Freeman-Halton test were used for the examination of qualitative data. Statistical significance was defined at $\mathrm{p}<0.05$.

\section{REsULTS}

Among 1000 consecutive cases referring to our outpatient department, 600 accepted to participate into our study program. However, only a total of 589 completed the inquiry form, of which 390 were male (66.2\%) and 199 (33.8\%) were female (M/F: 1.96). Evaluation of the per- centage of Internet use on an age based manner revealed that while $19.4 \%$ was < 30 years; 298 cases (50.6\%) were among 30-60 years and the remaining 177 cases (30.1\%) were over 60 years. With respect to their educational status again, intenet use among cases with primary, intermediate and high school degrees were 441 (74.9\%), 53 (9\%) and 95 (16.1\%), respectively. Lastly, evaluation of the cases based on their economical status showed that the percentage of internet use was $35.7 \%$ (210 cases) in cases with lower income, 63.3\% (373 cases) in intermediate and 1\% ( 6 cases) in cases with high income. Overall analysis of our data among subgroups demonstrated that there was a statistically significant relationship between the use of Internet and age $(p<0.001)$, gender $(p=0.048)$, educational status $(\mathrm{p}<0.001)$ and economical status $(\mathrm{p}=0.002)$ of the cases evaluated (Table 1). Of all the cases partecipating into the study program, 225 (38,2\%) acknowledged routine use of Internet; of these users 165 (73.3\%) were able to get the necessary healtcare information from the Internet (Table 2). Additionally among the internet users 169 cases (75.1\%) had an e mail account in order to institute a mutual cooperation. The overall attitude of the cases with respect to Internet use and search for medical information is summarized in Table 2. Concerning the area of interest for medical problems, our data clearly demon- 
Table 3.

Urologic problems searched in the internet

by the patients referred to our department $(n=225)$.

\begin{tabular}{|lcc|}
\hline Urinary system stone disease & $\mathbf{n}$ & $\%$ \\
\hline Non-cancer related kidney diseases & 41 & 18.2 \\
\hline Urologic cancers & 32 & 14.2 \\
\hline Sexual disorders & 32 & 14.2 \\
\hline Infertility & 22 & 9.7 \\
\hline LUTS & 21 & 9.3 \\
\hline Other subjects & 17 & 7.6 \\
\hline OAB & 12 & 5.3 \\
\hline Remaining (not-searching for any spesfic topic) & 9 & 4.0 \\
\hline
\end{tabular}

strated that while 41 cases (18.2\%) searched for urinary system stone disease, 32 (14.2\%) cases searched for noncancer related kidney diseases, 32 (14.2\%) for urologic cancer, 22 (9.7\%) for sexual disorders, 21 (9.3\%) for infertility, 17 (7.6\%) for lower urinary tract symptoms (LUTS), 9 (4\%) for overactive bladder (OAB) and 12 (5.3\%) for other medical subjects. The remaining 39 cases $(17.3 \%)$ however quoted that they did not search any subject related with health care from the Internet (Table 3).

\section{Discussion}

The rapid, easy and practical aspects of Internet search has made it a very useful tool to look for as well as obtain the required healthcare information on various medical problems. The efficiency of Internet in global circulation of the information is being accepted as the second revolutionary innovation following the invention of printing systems in 1447 by Johannes Gutenberg (1). The Internet has been first proposed to supply the military needs of USA army during nuclear armament after 1960's (Advanced Research Projects Agency of the United States Department of Defense to produce acomputer communications network - ARPANET) Following its introduction this system gained an enormous importance which brought it in an irresistable position as a highly important part of the daily life (8). At our present time this amazing revolution is further going on with the use of mobile phones which enable us for an extremely easy and practical search of all necessary information with an evident accelaration (9).

Determining the percentage of Internet use and its utility in developing countries is highly important. Taking this fact into account, we aimed to evaluate the attitude of the urology patients in Turkish society concerning the use of Internet facility in their daily life. Similarly to other studies dealing with the relationship between demographic variables and Internet use $(10,11)$, the evaluation of our data also showed a positive correlation between educational $(\mathrm{p}<0.001)$ and economical status $(p=0.002)$ of the cases and percentage of Internet use. Furthermore, there was a negative correlation between the age of the cases and the percentage of Internet use $(\mathrm{p}<0.001)$, and a positive correlation in favor of male gender $(p=0.048)$. Similarly, in their original study, Kendra et al. were able to show a positive correlation between Internet use and educational as well as economical status of the evaluated population (10).

They also demonstrated that younger generation used the Internet in a more common and practical manner than adults (12). In relation to this subject Pew Internet and American Life Project studies again well demonstrated that the use of Internet increased steadily in older ages with values of $2 \%$ in 1996, 15\% in 2002 and $22 \%$ in $2004(13,11)$. In the same study they recorded a higher Internet use rate (68\%) among subjects with higher educational degree (university) when compared with relatively lower educational levels (high school graduated) (52\%) (11). Although no direct relationship between socioeconomic status and Internet use could be shown, education opportunity and being able to buy a computer system indicate an indirect positive relationship between these two important parameters.

Studies point out that the use of Internet is enormously inceased during the last 2 decades. In relation with this subject, Internet World States 2012 data revealed that the whole worldwide number of users is 2.405.518.376 (14) and 200 million in USA (15). With respect to these values, in our country Turkish Statistics Institution has announced that the percentage Internet users among 1674 class age was $47.4 \%$ whereas the percentage of regular users seemed to drop to $37.8 \%$ (16).

In addition to the common use of the Internet in every part of daily life, its use is apparently increasing worldwide also in healthcare sector (17). Currently Internet has proven itself to have an extraordinary potential in offering the necessary healthcare information to both normal healthy people as well as to patients suffering from different pathologies (18). In accordance with this fact again it has been reported that the use of Internet in order to obtain the necessary pathology-related information is again evidently increasing among the urology patients (19).

Studies indicate that as much as one third of Internet user patients share the obtained information with their physicians (4). As a result of the all these achievements, the paradigm between patient and physician seems to change in a considerable manner (7).

Last but not least, it is very well known that the specific aims of using the Internet in healthcare system is to obtain information (content), share the obtained information (community) and send this information to others (communication, e-mail) (7). Furthermore the use of Internet in this sector may give the advantages of communication between patients and physicians as well as getting the necessary support from family, friends and related environment (20). Of course, another additional advantage will be to get appoinment from the hospitals as well as physician' offices in a quick and practical manner. In their study dealing with emergency department cases Pourmand et al. noted that $92.6 \%$ of the cases used the Intenet and of these users $94.5 \%$ had a personal email address (21). Michele et al. reported that among all Internet users, 55\% used their personal e-mail addresses to cooperate with medical institutions providing medical 
support (22). Pew Internet and American Life Project 2009 study reported the use of personal e-mail address among the Internet users to be $91 \%$ (23). In our current study, $75.1 \%$ of our cases reported to have a personal e-mail address. The use of e-mail in healthcare sector will make the communication between medical support providers and patients more practical and quicker. Additionally, patient follow-up, scheduling the appoinments and planning other medical procedures will be more practical in a highly effective manner (24).

Concerning this issue, Schwartz et al. reported that while $7.6 \%$ of the Internet user patients shared this information with their physicians in a permanent manner, 52,6\% shared it occasionally (10). However Taylor et al. reported that $53 \%$ of Internet user patients shared these data with their physicians (25). Similarly to reported literature, according to our data $39.7 \%$ of the participants of our study shared the Internet derived information with their physicians in a permanent manner which in turn again indicated the highly important role of Internet use for a proper and cooperative communication between the patients and physicians.

Regarding the use of Internet in order to get information about present health related problems, it has been shown that the patients may look for either specific or general topics on this aspect. With respect to this issue, in their study, Nicholas et al. found that out of 1322 Internet users $97 \%$ searched for specific topics related with their problems (26), while this rate has been reported to be $79 \%$ by Kendra et al. (10). Our data showed that among the participants referring to an urology department, 82.7 $\%$ searched for urology related topics (Table 3). Further evaluation of the topics searched demonstrated that 18.2 $\%$ of our cases searched for urolithiasis, 14\% searched for urologic cancers and 14\% for general kidney diseases. In another study, concerning the inquiries in patients from 7 countries in Europe, Andreassen et al. reported that $52 \%$ of the cases searched for specific topics in Internet [4]; Pew Internet and American Life Project 2013 study revealed that $55 \%$ of the users searched for specific diseases or medical conditions (27).

The relatively lower rate of search for some specific medical topics demonstrated in our study could be related to the fact that patients suffering from sexual as well as andrologic problems could refrain from using Internet for this aim.

One further aspect of Internet use is the benefit for the patients to discuss about Internet-obtained data during the interview with their physician. There are studies in the literature dealing with consideration and satisfaction of the patients with respect to the Internet derived data $(11,28)$. In our current study $77.2 \%$ of the cases expressed the usefulness of the data obtained from Internet. Ybarra et al. were able to show that $73.3 \%$ of their cases were satisfied with the data obtained and $78 \%$ of the cases stated that the Internet derived data eased their daily life conditions (22). Baker et al. reported that $67 \%$ of relatively older users noticed that Internet data let them to realize their healthcare problems in a more understandable manner (28). Last but not least in the European Union Eurobarometer inquiry study, $41.5 \%$ of the participants found the Internet derived data were highly useful to deal with their healthcare problems (29). Another aspect of Internet use is the reliance of users on the data obtained with respect to their adequacy and safety: a concern that has been subjected to numerous studies in the literature (30). In relation with this subject, $53.1 \%$ of the cases in our study found the Internet obtained medical data reliable and useful; Traver et al. reported the rate of treliability in urology and nephrology web sites as $41 \%$ and $51 \%$ respectively (31). On the other hand however, in their original study, Smith et al. found the Internet derived data for medical problems as reliable in $21 \%$, adequate in $77 \%$ and useless in $2 \%$ of the cases evaluated (6). Depending on our as well as on similar published data in the literatüre, we may say that patients seemed to be careful and selective in using Internet to derive information for their medical problems.

The limited number of subjects evaluated and the lack of data concerning a detailed evaluation of the web sites used as well as their individual reliability from patient' perspective are possible limitations of our study. However, we believe that despite all these certain limitations, in consideration of the highly limited data regarding the use of internet among urology patients in our country as well as in developing countries, our findings could be accepted as valuable enough to give further information about the use of Internet in healthcare system. We again believe that further studies with larger number of participants and focusing on specific parameters are certainly needed.

\section{Conclusion}

In the light of our data as well as of the published literature findings, it seems that younger patients with higher educational status tend to use Internet to derive information about their health problems in a more common and efficient manner. The majority of these cases share all these information with their physicians during their visit. We believe that use of Internet data in a proper manner will provide reliable information with respect to the diagnosis and management of the health problems which will contribute to patient-physician relationship in a more positive manner. All physicians should consider this fact seriously and make their future plans in the light of Internet based activities which provides numerous advantages.

\section{References}

1. Ullrich PF Jr, Vaccaro AR. Patient education on the internet: opportunities and pitfalls. Spine (Phila Pa 1976). 2002; 27:E185-8.

2. Vance K, Howe W, Dellavalle RP. Social internet sites as a source of public health information. Dermatol Clin. 2009; 27:133-6.

3. Rainee L. Internet, broadband, and cell phone statistics. Washington DC, USA: Pew Internet and American Life Project. 2010 .

4. Andreassen HK, Bujnowska-Fedak MM, Chronaki CE, et al. European citizens' use of E-health services: a study of seven countries. BMC Public Health. 2007; 7:53. 
5. Goldsmith J. How will the Internet change our health system? Health Aff (Millwood). 2000; 19:148-56.

6. Smith RP, Devine P, Jones $H$, et al. Internet use by patients with prostate cancer undergoing radiotherapy. Urology. 2003; 62:273-7.

7. Mc Mullan M. Patients using the Internet to obtain health information: how this affects the patient-health professional relationship. Patient Educ Couns. 2006; 63:24-8.

8. Doyle DJ, Ruskin KJ, Engel TP. The Internet and medicine: past, present, and future. Yale J Biol Med. 1996; 69:429-37.

9. Smith A. Mobile Access. Washington DC, USA: Pew Internet and American Life Project. 2010.

10. Schwartz KL, Roe T, Northrup J, et al. Family medicine patients' use of the Internet for health information: a MetroNet study. J Am Board Fam Med. 2006; 19:39-45.

11. Fox S. Older Americans and the Internet. Washington DC, USA: Pew Internet and American Life Project. 2004.

12. Fast AM, Deibert CM, Boyer C, et al. Partial nephrectomy online: A preliminary evaluation of the quality of health information on the Internet. BJU Int. 2012; 110:E765-9.

13. Pautler SE, Tan JK, Dugas GR, et al. Use of the internet for selfeducation by patients with prostate cancer. Urology. 2001; 57:230-3.

14. Internet World Stats. Internet users in the Worl. 2012; Available at:http://www.internetworldstats.com/stats.htm. Accessed December 2013.

15. Sadasivam RS, Kinney RL, Lemon SC, et al. Internet health information seeking is a team sport: analysis of the Pew Internet Survey. Int J Med Inform. 2013; 82:193-200.

16. T.C. Basbakanlık Türkiye Istatistik Kurumu Haber Bülteni. Hanehalkı Bilisim Teknolojileri Kullanım Arastırması (Turkey Prime Ministry Turkish Statistical Institute News Bulletin. Household informatics technology usage investigation). 2012; Available at:http://www.tuik.gov.tr. Accessed December 2013.

17. Eng TR, Maxfield A, Patrick K, et al. Access to health information and support: a public highway or a private road? JAMA. 1998; 280:1371-5.

18. Weaver JB 3rd, Mays D, Lindner G, et al. Profiling characteris- tics of internet medical information users. J Am Med Inform Assoc. 2009; 16:714-22.

19. Hellawell GO, Turner KJ, Le Monnier KJ, Brewster SF. Urology and the Internet: an evaluation of internet use by urology patients and of information available on urological topics. BJU Int. 2000; 86:191-4.

20. Mechanic D. How should hamsters run? Some observations about sufficient patient time in primary care. BMJ. 2001; 323:266-8.

21. Pourmand A, Sikka N. Online health information impacts patients' decisions to seek emergency department care. West J Emerg Med. 2011; 12:174-7.

22. Ybarra ML, Suman M. Help seeking behavior and the Internet: a national survey. Int J Med Inform. 2006; 75:29-41.

23. Jones S, Fox S. Generations Online in 2009. New York, NY, USA: Pew Internet and American Life Project. 2009.

24. Anderson JG, Rainey MR, Eysenbach G. The impact of CyberHealthcare on the physician-patient relationship. J Med Syst. 2003; 27:67-84.

25. Taylor H. Cyberchondriacs. In: On the Rise? . New York, NY, USA: Harris Interactive. 2010.

26. Nicholas D, Huntington P, Gunter B, et al. The British and their use of the web for health information and advice: a survey. Aslib Proc. 2003; 55:261-76.

27. Fox S. Health Online. New York, NY, USA: Pew Internet and American Life Project. 2013.

28. Baker L, Wagner TH, Singer S, Bundorf MK. Use of the Internet and e-mail for health care information: results from a national survey. JAMA. 2003; 289:2400-6.

29. European Commission Survey of Online Health Information. 2003; Available at http://europa.eu.int/comm/public_opinion larchives/eb/eb59/eb59_rapport_final_en.pdf; Accessed December 2013.

30. Ziebland S, Chapple A, Dumelow C, Evans J, Prinjha S, Rozmovits L.How the internet affects patients' experience of cancer: a qualitative study. BMJ. 2004; 6;328:564

31. Traver MA, Passman CM, LeRoy T, et al. Is the Internet a reliable source for dietary recommendations for stone formers? J Endourol. 2009; 23:715-7.

\section{Correspondence}

Cahit Sahin, MD (Corresponding Author)

cahitsahin129@gmail.com

Murat Tuncer, MD

Ozgur Yazici, MD

Alper Kafkasli, MD

Utku Can, MD

Bilal Eryildirim, MD

Kemal Sarica, MD

Dr. Lutfi Kirdar Training and Research Hospital, Urology Clinic

Gömeç sok. Sabancı -2 Sitesi Al Kat 4 Daire 24 Acıbadem/Kadıköy Istanbul, Turkey

Orhan Koca, MD

Hydarpasa Numune Training and Research Hospital, Urology Clinic Istanbul, Turkey 